\title{
The dynamics of changing internal jugular veins diameter based on increasing head elevation angle
}

\author{
Aleksandr L. Urakov, Anton A. Kasatkin, Anna R. Nigmatullina1
}

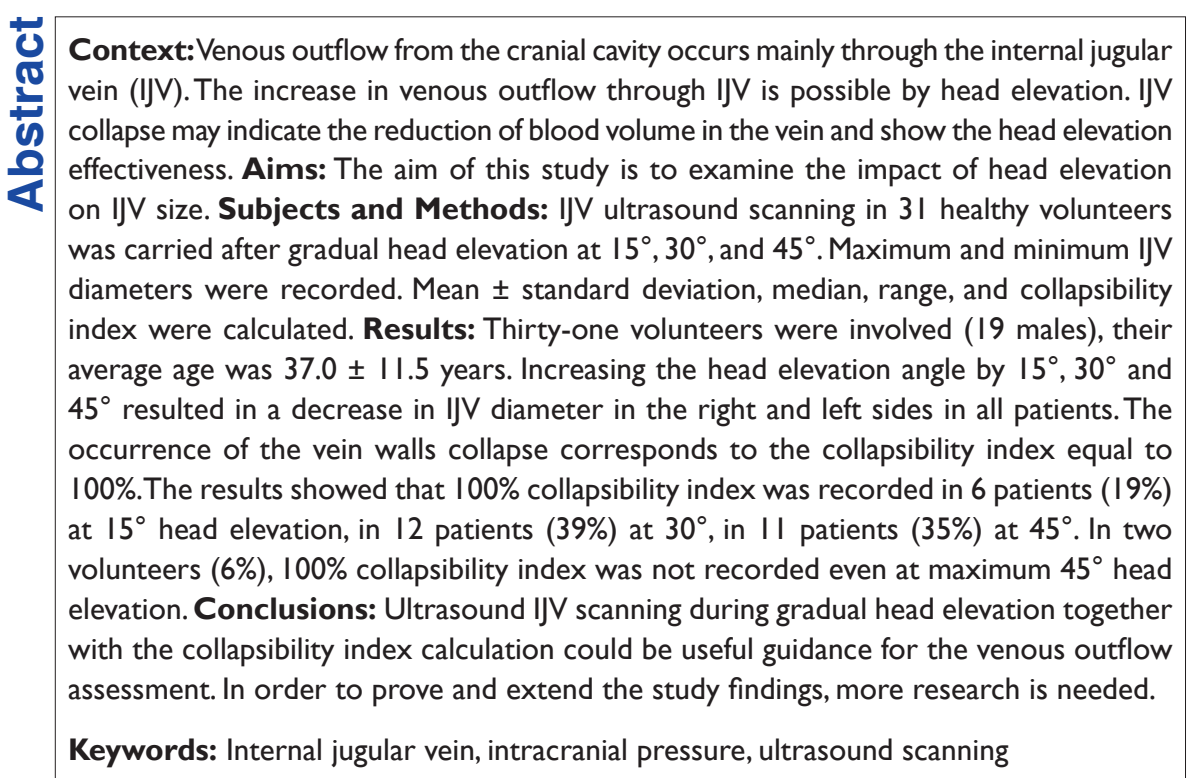

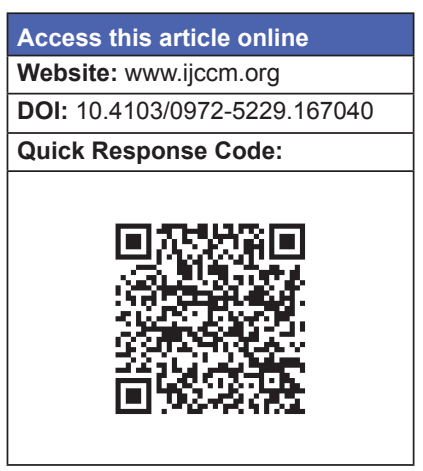

\section{Introduction}

Head elevation at $15-45^{\circ}$ could reduce intracranial pressure due to increased venous outflow from the cranial cavity and reduction of intracranial venous blood volume. ${ }^{[1,2]}$ However, the common practice of head elevation in patients with traumatic brain injury has been questioned lately, as some studies showed that the elevation $>30^{\circ}$ could reduce cerebral perfusion pressure and mean pressure in the carotid artery. ${ }^{[3]}$ Since the venous outflow from the cranial cavity is mainly through the internal jugular veins (IJVs), their diameter dynamics may help to determine the minimum angle of an individual patient head elevation providing the maximum outflow of venous blood. A number of studies

From:

Department of General and Clinical Pharmacology, Izhevsk State Medical Academy, ${ }^{1}$ Department of Anesthesiology and Intensive Care, Clinical Hospital, Izhevsk, Russia

\section{Correspondence:}

Dr. Anton A. Kasatkin, Karl Marks Street 278-45, 426008 Izhevsk, Russia E-mail: ant-kasatkin@yandex.ru have examined the impact of passive leg elevation and trendelenburg position on IJV size change. ${ }^{[4,5]}$ The impact of head elevation on IJV size change is not studied yet.

The aim of this study is to examine the impact of head elevation on IJV size.

\section{Subjects and Methods}

Ultrasound IJV was scanning and their diameter measurements were carried out in 31 healthy volunteers using Siemens Acuson S2000 ultrasound system(USA) and

This is an open access article distributed under the terms of the Creative Commons Attribution-NonCommercial-ShareAlike 3.0 License, which allows others to remix, tweak, and build upon the work non-commercially, as long as the author is credited and the new creations are licensed under the identical terms.

For reprints contact: reprints@ medknow.com

How to cite this article: Urakov AL, Kasatkin AA, Nigmatullina AR. The dynamics of changing internal jugular veins diameter based on increasing head elevation angle. Indian J Crit Care Med 2015;19:610-2. 
5-14 MHz linear transducer. The study was conducted in a hospital bed Futura Plus by Merivaara Company (Finland).

The IJV scanning was carried out in 2 min after placing the volunteers in a horizontal position on their back, and in 2 min each time after the volunteers had attained the new position due to the gradual lifting the bed back section at the $15^{\circ}, 30^{\circ}$, and $45^{\circ}$. The ultrasonic sensor was placed on the neck of the patient between the heads of sternocleidomastoid muscle, and veins cross-scanning was carried out on both sides. The maximum and minimum vein diameter sizes were recorded. Quantitative data are presented as mean \pm standard deviation, median, range, and collapsibility index. IJV collapsibility index was calculated as: IJV-confidence interval $(\mathrm{CI})=([\mathrm{Dmax}-\mathrm{Dmin}] / \mathrm{Dmax}) \times 100 \%$. The IJV-CI was derived via M-mode assessment of the variation in the veins diameter (minimum versus maximum). The research plan was approved by the Ethics Committee of the Izhevsk State Medical Academy based on the principles set in the World Medical Association Declaration of Helsinki.

\section{Results}

Ultrasound examination of right and left IJV state was carried out in 31 healthy volunteers [Table 1].

A gradual increase of the head elevation angle from $0^{\circ}$ to $45^{\circ}$ was followed by IJV diameter decrease [Table 2].

Veins collapse in the human subjects was recorded at different head elevation angles. In 6 volunteers (19\%), complete IJV collapse was recorded at $15^{\circ}$ head elevation while in two volunteers (6\%) vein collapse was not recorded even at $45^{\circ}$ head elevation.

Collapsibility index dynamics based on volunteers' head elevation angle is shown in Table 3.

IJV ultrasound scanning allows to define IJV size change due to head elevation and to calculate collapsibility index [Figure 1].

We revealed the correlation between the mean IJV diameter and the collapsibility index. The correlation coefficient (right and left) between D-mean and IJV-CI was -0.72 and -0.75 , respectively, which means a strong negative correlation.

\section{Discussion}

It is traditionally considered that head elevation results in ICP decrease. ${ }^{[6,7]}$ In particular, it was shown that in

\begin{tabular}{lc}
\hline Table I: Demographic of the study group & \\
\hline Study sample characteristics & Number (\%) \\
\hline General demographics & \\
Number of volunteers & 31 \\
Gender, \%female & $19 / 31(61)$ \\
Mean age \pm SD (years) & $37.0 \pm 11.5$ \\
[median, range] & {$[36,19-66]$} \\
Total volunteers & 31 \\
Total data pairs measured & 775 \\
[per patient] & 25 \\
\hline
\end{tabular}

\begin{tabular}{|c|c|c|c|c|}
\hline \multirow{5}{*}{$\begin{array}{l}\text { Head } \\
\text { elevation, } \\
\text { degrees }\end{array}$} & \multicolumn{4}{|c|}{ Diameter of IJV, mm } \\
\hline & \multicolumn{2}{|c|}{ Right } & \multicolumn{2}{|c|}{ Left } \\
\hline & $\mathbf{D}_{\min }$ & $\mathbf{D}_{\max }$ & $\mathbf{D}_{\min }$ & $\mathbf{D}_{\max }$ \\
\hline & Mean \pm SD & Mean \pm SD & Mean \pm SD & Mean \pm SD \\
\hline & Median & Median & Median & Median \\
\hline \multirow[t]{2}{*}{$\overline{0^{\circ}}$} & $6.4 \pm 2.6$ & $8.5 \pm 2.6$ & $6.3 \pm 2.7$ & $7.8 \pm 2.8$ \\
\hline & 6.2 & 5.5 & 5.5 & 7.2 \\
\hline \multirow[t]{2}{*}{$15^{\circ}$} & $2.8 \pm 2.6$ & $4.8 \pm 3.4$ & $3.2 \pm 2.3$ & $5.0 \pm 2.7$ \\
\hline & 2.0 & 2.8 & 2.8 & 5.2 \\
\hline \multirow[t]{2}{*}{$30^{\circ}$} & $1.5 \pm 2.2$ & $2.9 \pm 2.6$ & $1.6 \pm 1.9$ & $3.2 \pm 2.4$ \\
\hline & 0.6 & 1.0 & I.0 & 2.4 \\
\hline \multirow[t]{2}{*}{$45^{\circ}$} & $0.8 \pm 1.5$ & $1.9 \pm 2.3$ & $0.7 \pm 1.3$ & $1.8 \pm 2.0$ \\
\hline & 0 & 0 & 0 & 1.2 \\
\hline
\end{tabular}

IJV: Internal jugular vein; SD: Standard deviation

\begin{tabular}{|c|c|c|}
\hline \multirow{4}{*}{$\begin{array}{l}\text { Head } \\
\text { elevation, } \\
\text { degrees }\end{array}$} & \multirow{3}{*}{\multicolumn{2}{|c|}{$\begin{array}{c}\text { IJV-CI, \% } \\
\text { Mean } \pm \text { SD } \\
\text { Median }\end{array}$}} \\
\hline & & \\
\hline & & \\
\hline & Right & Left \\
\hline $0^{\circ}$ & $\begin{array}{c}26.0 \pm 16.4 \\
22.5\end{array}$ & $\begin{array}{c}21.3 \pm 11.3 \\
17.9\end{array}$ \\
\hline $15^{\circ}$ & $\begin{array}{c}51.3 \pm 25.3 \\
44.6\end{array}$ & $\begin{array}{c}41.4 \pm 22.0 \\
40.0\end{array}$ \\
\hline $30^{\circ}$ & $\begin{array}{c}61.7 \pm 37.3 \\
62.2\end{array}$ & $\begin{array}{c}64.6 \pm 29.9 \\
66.7\end{array}$ \\
\hline $45^{\circ}$ & $\begin{array}{c}82.2 \pm 30.1 \\
100.0\end{array}$ & $\begin{array}{c}77.8 \pm 34.9 \\
100.0\end{array}$ \\
\hline
\end{tabular}

severe pediatric traumatic brain injury, the relationship between change in head of the bed and change in intracranial pressure was negative and linear.

Decreased intracranial pressure associated with the head elevation is related to the increased venous outflow from the cranial cavity and decreased intracranial venous blood volume. ${ }^{[1,2,8]}$ The major venous blood outflow from the cranial cavity in a supine human occurs through the IJVs. As it was shown before, the IJVs ultrasound scanning provides accurate records of changes in their diameters due to human body position change, performing 


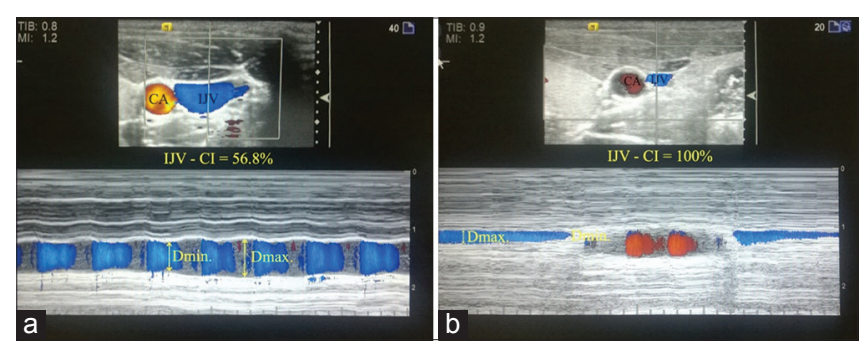

Figure I: Measuring left internal jugular vein diameter in healthy volunteer using M-mode ultrasonography at $0^{\circ}$ (a) and $30^{\circ}$ (b) head elevation. Based on the measurements in this example, the confidence interval-internal jugular vein would be $41.7 \%$ and $100 \%$, respectively

functional tests, and volume expansion. ${ }^{[4,5]}$ Besides, an inverse correlation between the volume status values and collapsibility index was revealed. ${ }^{[9,10]}$ The increase in collapsibility index value was associated with a reduction of venous blood volume. Thus, IJV collapse and the collapsibility index value equal to $100 \%$ may indicate the reduction of local blood volume in IJV to a minimum and show the head elevation effectiveness. Our results suggest that the elevation of the head end is accompanied by a decrease in IJVs diameter up to their collapse. When the image of venous walls collapse appeared on the ultrasound scanner screen, collapsibility index reached $100 \%$.

Thus, in 6 subjects (19\%) collapsibility index reached $100 \%$ at $15^{\circ}$ head elevation and did not change with further head elevation. However, in $6 \%$ of volunteers $100 \%$ collapsibility index was not recorded even at maximum $45^{\circ}$ head elevation.

The results showed the possibility of using IJV ultrasound scanning for collapsibility index evaluation while increasing elevation angle. The image of IJV collapse on the ultrasound scanner screen can be accepted as criterion of head elevation effectiveness in clinical settings. Our findings show that IJVs ultrasound scanning may be recommended to doctors as quick and noninvasive additional method of evaluating the efficacy of therapy aimed at improving venous outflow from the cranial cavity in an individual patient.
However, for better accuracy, we need additional large-scale prospective research to study the relationship between IJVs collapsibility index and intracranial and intravenous pressure characteristics. Nevertheless, this study forms the basis for further related clinical research.

\section{Financial support and sponsorship \\ Nil.}

\section{Conflicts of interest}

There are no conflicts of interest.

\section{References}

1. Rangel-Castillo L, Robertson CS. Management of intracranial hypertension. Crit Care Clin 2006;22:713-32

2. Sankhyan N, Vykunta Raju KN, Sharma S, Gulati S. Management of raised intracranial pressure. Indian J Pediatr 2010;77:1409-16.

3. Durward QJ, Amacher AL, Del Maestro RF, Sibbald WJ. Cerebral and cardiovascular responses to changes in head elevation in patients with intracranial hypertension. J Neurosurg 1983;59:938-44.

4. Kim WH, Lee JH, Lee SM, Kim CS, Kang R, Yoo CS, et al. The effect of passive leg elevation and/or trendelenburg position on the cross-sectional area of the internal jugular vein in infants and young children undergoing surgery for congenital heart disease. Anesth Analg 2013;116:178-84.

5. Schreiber SJ, Lambert UK, Doepp F, Valdueza JM. Effects of prolonged head-down tilt on internal jugular vein eross-sectional area. Br J Anaesth 2002;89:769-71.

6. Goldberg RN, Joshi A, Moscoso P, Castillo T. The effect of head position on intracranial pressure in the neonate. Crit Care Med 1983;11:428-30.

7. Meixensberger J, Baunach S, Amschler J, Dings J, Roosen K. Influence of body position on tissue-pO2, cerebral perfusion pressure and intracranial pressure in patients with acute brain injury. J Neurosurg $1983 ; 59: 938-44$.

8. Feldman Z, Kanter MJ, Robertson CS, Contant CF, Hayes C, Sheinberg MA, et al. Effect of head elevation on intracranial pressure, cerebral perfusion pressure, and cerebral blood flow in head-injured patients. J Neurosurg 1992;76:207-11.

9. Stawicki SP, Braslow BM, Panebianco NL, Kirkpatrick JN, Gracias VH, Hayden GE, et al. Intensivist use of hand-carried ultrasonography to measure IVC collapsibility in estimating intravascular volume status: Correlations with CVP. J Am Coll Surg 2009;209:55-61.

10. Kent A, Patil P, Davila V, Bailey JK, Jones C, Evans DC, et al. Sonographic evaluation of intravascular volume status: Can internal jugular or femoral vein collapsibility be used in the absence of IVC visualization? Ann Thorac Med 2015;10:44-9. 